\title{
Acute Normovolemic Hemodilution: A Practical Approach
}

\author{
Liana Maria Torres De Araújo ${ }^{1}$, Luis Vicente Garcia ${ }^{2}$ \\ ${ }^{1}$ Hospital das Clínicas at Ribeirão Preto, Ribeirão Preto, Brazil; ${ }^{2}$ Faculty of Medicine, Hospital das Clínicas at Ribeirão Preto, \\ Ribeirão Preto, Brazil. \\ Email: liana.araujo@ufba.br
}

Received October $14^{\text {th }}, 2012$; revised November $13^{\text {th }}, 2012$; accepted December $16^{\text {th }}, 2012$

\begin{abstract}
Justifications: Perioperative allogeneic blood transfusion can be reduced or even completely avoided by using a set of different strategies: meticulous hemostasis, the use of pharmaceutical agents that assist in the process of coagulation/ fibrinolysis, the use of blood substitutes, induced hypotension, preoperative autologous blood donation, collection and reinfusion of autologous blood during the operation, as well as from acute normovolemic hemodilution (ANH). Contents: ANH consists of taking a percentage of the patient's blood volume and a concurrent infusion of acellular fluids in order to maintain normovolemia. As a consequence, a hemodiluted patient will lose less blood cells for each blood volume that is lost during the surgical procedure. The aim of this study is to clarify doubts and provide practical information relative to the procedure of ANH through the author's own experiences as well as literary examples. Conclusions: ANH is an easy and cheap technique performed during the intraoperative period useful to reduce the use of hemoderivatives.
\end{abstract}

Keywords: Hemodilution; Blood Transfusion; Anesthesia

\section{Introduction}

Acute normovolemic hemodilution (ANH) has been used since the 60's and its aim is to reduce or even avoid the need for transfusion of homologous blood during the perioperative period [1-3]. It consists of withdrawing a percentage blood volume from the patient and simultaneous infusion of acellular fluids in order to maintain the volume. This procedure will make the patient anemic, although although he will remain normovolemically and hemodynamically stable [4]. With the exception of extreme hemodilution situations, the capacity for tissue oxygen supply and demand will not be affected [5].

While there are fine meta-analysis on this subject $[3,6]$ the main point of this study is to elicit common questions on the subject beyond provide some practical strategies based on recent studies and the experience of the authors.

\section{Basic Principles}

\subsection{Indications and Selection of Patients}

The concept of withdrawing a percentage of blood and leaving the patient anemic and normovolemic, is intended to minimize the loss of red blood-cells during surgery $[1-3,6]$. As the hemoglobin concentration is reduced through dilution, the blood that is lost during surgery will contain less hemoglobin. For example: A loss of $1000 \mathrm{ml}$ of blood during surgical procedure, from a patient that has a hemoglobin concentration of $14 \mathrm{~g} / \mathrm{dl}$, will result in a loss of 140 grams of hemoglobin; while in a patient who was hemodiluted to a concentration of 8 $\mathrm{g} / \mathrm{dl}$, the loss will be 80 grams; in other words a saving of 60 grams of hemoglobin. Upon conclusion of the surgery, following the period of greatest intraoperative blood loss or at any other critical moment, fresh autologous blood will be returned to the patient [4].

ANH can be performed in any procedure that anticipates a large loss of blood [7]. It is more frequently performed in cardiac procedures (with or without extracorporeal circulation); neurosurgery (tumors and aneurysms); orthopedics (escolioses and prosthetics); vascular (aneurysms and reconstructive surgery); thoracic (pneumonectomies and lobotomies); urological (prostatectomys, cystectomies and nefrectomias) and general surgery (greater intestinal surgery and tumor resections) [8].

Patients that obtain the most benefit from this procedure are those that have rare blood groups and young patients who have never been transfused [9]. Not all patients are eligible for ANH and not all surgical procedures require ANH. Patients expecting low blood loss during surgery clearly will not benefit from this procedure. Furthermore, the removal of small blood volumes during the hemodilution process will not result in any economy of autologous blood from the patient $[7,8]$.

The greater the initial hematocrit level of the patient, the greater the volume collected for reaching the hematocrit 
target. So, in elective surgeries, when the patient is anemic, strategies for optimizing the hematocrit level should be utilized: erythropoietin (50 - $100 \mathrm{mg} / \mathrm{kg}, 3$ times/week, via subcutaneous), ferrous sulphate (200 - $400 \mathrm{mg} /$ day) and folic acid (0.5 - $1.0 \mathrm{mg} /$ day) [10].

\subsection{Contraindications}

The most common for ANH are severe sepsis; acute respiratory insufficiency; acute anuric renal insufficiency and hemorrhagic shock secondary to trauma. Patients suffering from severe coronary arterial disease should only be indicated after careful assessments of the risks and benefits of this procedure [11].

Patients with light degrees of anemia, renal or respiratory disease, history of cerebral vascular accident, congestive cardiac or coronary disease need to be well clinically evaluated before the indication of ANH [12].

\subsection{Advantages}

It is not necessary to change the anesthetic technique in patients submitted for ANH, so it could be performed under locorregional anesthesia (for example, in the case of knee or hip prosthesis) [8].

Blood collected and stored in the actual operating theatre is rich in platelets and coagulant factors. Although some studies demonstrated an increase in bleeding during intraoperative, also due to the dilution of the platelets and coagulant factors, most of them argued that perfect hemostasis reestablishes itself after the infusion of the previously collected blood, which is rich in procoagulant components. So despite the increased bleeding during surgery, total blood loss (during the whole perioperative period) is reduced by using this technique [13-15].

Compared with the preoperative autologous blood donation (PAD), ANH has various advantages. It costs less, it can be performed in emergency sceneario and also in patients who, for religious motives, refuse hemocomponent transfusions [16]. Furthermore, with PAD, one cannot rule out the risks from conventional autologous transfusions (including allergic reactions and errors in the process of collection and storage) [17].

In respect to the blood cell salvage during the intraoperative period, ANH has the advantage of preserving platelets and coagulant factors. These would normally be lost during the process of aspirated blood filtration [18]. Cell salvage is more high-priced and it requires this sophisticated and expensive equipment and also trained staff to operate the machine $[19,20]$.

\section{Hemodilution Procedure}

\subsection{Timing for Collection}

The ideal moment for making the collection is directly after induced anesthesia, before surgery starts, but it can be performed at anytime during the intraoperative period, before the moment of greatest blood loss [1]. The entire process of collection should not exceed 40 to 50 minutes $[1,3]$.

\subsection{Technique}

The blood can be collected from a vein or an artery. Placing a catheter $20 \mathrm{G}$ in an artery will permit sufficient quantity of blood to be collected, as the patient's blood pressure acts as a “pump”. Using the artery for collecting the blood has the disadvantage of not allowing invasive arterial pressure measurement simultaneously. This problem can be remedied by puncturing two arteries, one to be used for the measurement of the arterial pressure. Alternatively, if a three-way connector is used, only one artery will be required with intermittent monitoring of arterial pressure. Arterial monitoring intervals should not exceed three minutes. In order to collect blood from a vein bigger catheters are necessary (16 G or $14 \mathrm{G}$ ). In this situation, the collection happens in a passive way, by gravity. When available, a central venous catheter can be used, taking the precaution of not using this channel to replace liquids during collection process [1,21].

Bags used for the collection of blood are the equal from voluntary donation [5]. In conventional donations, the two or three satellite bags are used for blood fractionation but in ANH they have no use and can be discarded. At their extremities, those bags contain a calibrated metallic needle to collect blood but using connectors between the bag and the arterious or venous site of collection in ANH there is no need to use the needle [1].

The collected blood is weighed on a conventional digital balance. It should be assumed that each milliliter of blood is equivalent to 1 (one) gram. In order to promote homogenization between the blood and the anticoagulant, it is necessary to constantly stir the blood bag. This can be done manually or by an automated system. Each bag should contain 450 - $500 \mathrm{ml}$ of blood [2,3].

As soon as the bag has $500 \mathrm{ml}$, it should be disconnected and labeled with the following information: sequential number of collection, name of the patient, volume of blood and the time of the collection. It should be stored at the ambient temperature (approximately 20 $\mathrm{C}$ ) for a maximum period of 6 hours. After this, it should be refrigerated at zero degrees Celsius, according to the directions from the American Association of Blood Banks $[1,4]$.

\subsection{Volume to Be Collected}

The calculation of the volume to be collected is made by using the formula proposed by Gross, in 1983, which uses the following elements: $\mathrm{BV}=\mathrm{EBV}(\mathrm{Htci}-\mathrm{Htct}) /$ 
hematocrit average, where: BV is the blood volume, that is, the volume to be collected for obtaining the required target hematocrit; EBV is the expected blood volume loss; Htci is the initial hematocrit; Htct (target hematocrit) is the hematocrit to be reached, and the average hematocrit is the arithmetical average between the initial hematocrit and the target hematocrit. It is estimated that the volemia (EBV) is from 60 to $65 \mathrm{ml} / \mathrm{kg}$ in women and 67 to 70 $\mathrm{ml} / \mathrm{kg}$ in men [22].

The choice of the hematocrit target depends on the surgical procedure involved and the functional reserve of each patient. Therefore targets very close to the initial hematocrit level will result in a small volume of blood to be collected, which will frustrate the principal objective of the procedure that is to economize in homologous blood. On the other hand, hematocrit targets too distant from the initial level require the patient to have sufficient functional reserves in order to support the amount of fluid replacement that should be infused. As an example: in a male patient, weighing $90 \mathrm{~kg}$ and an initial hematocrit of $40 \%$, where it is intended to commence surgical procedure with a hematocrit of $24 \%$, you need to collect approximately $3150 \mathrm{ml}$ of blood. It should be pointed out that the collected bags will have decreasing hematocrits, or, the first bag collected will be richer in red blood cells than the following ones [3].

\subsection{Volemic Replacement}

Acellular fluids (colloids or crystalloids) should be administered in parallel the collection in order to maintain the euvolemia [3,6]. Due to escaping crystalloid fluids into the interstitial space after 30 to 40 minutes, the volume for replacing should be three times the volume removed, i.e. for each $1 \mathrm{ml}$ of blood removed; $3 \mathrm{ml}$ of crystalloid solution should be infused [23]. Lactated Ringer solution is preferably because it has a lower incidence of acidosis, (a larger charge of chlorine in the saline solution tends to cause hyperchloremic metabolic acidosis) $[24,25]$. Glucose solution should not be used due to its low plasmatic expansion properties and to its ability to cause cellular edema and hyperglycemia [23].

As a way of reducing the volume administered colloidal solutions can be used. Therefore, for every $1 \mathrm{ml}$ withdrawn, it is necessary to reinfuse only $1 \mathrm{ml}$ of colloidal solution. However, each colloidal solution has its own side effects or restrictions (costs, potential alergogenic properties, nephrotoxic and coagulation damage) [26].

An alternative method is to replace collected blood in a sequence: for a collection of $2000 \mathrm{ml}$, the first 1000 milliliters withdrawn are replaced with colloid solutions in the proportion of 1:1 and the remaining $1000 \mathrm{ml}$ will be replaced in the proportion of $2000 \mathrm{ml}$ of crystalloid solution (2:1). Therefore, the patient will receive $3000 \mathrm{ml}$ of volume for replacing instead of $6000 \mathrm{ml}$, if the re- placement was made exclusively with crystalloids.

The use of hypertonic solution $7.5 \%$ as a replacement fluid had recent been suggested by this authors. Half of the volume collected being replaced by conventional crystalloid solutions and the other half with a fixed value of $4 \mathrm{ml} / \mathrm{kg}$ of $7.5 \%$ saline solution [27]. The $7.5 \%$ solution can compensate the increasing of fluid in the extravascular compartment, returning it intra-vascularly and reducing the edema in the patient [28]. In an still experimental but hypertonic solution demonstrated potential benefit in regulating the inflammatory response, improving signal transduction and alleviating cytotoxic response [29,30].

During the intraoperative period other losses (insensitive, fasting and diuresis) should be replaced as habitually [5].

\subsection{Safety Margin during the Intraoperative Period}

Basic hemodynamic parameters should be monitored during the performance of ANH [31]. The utilization of invasive arterial pressure measurement is of great assistance, during both collection and surgical procedure. Furthermore, an arterial catheter provides sequential laboratory exams when necessary. A central venous catheter is desirable, but not obligatory. More invasive monitoring, such as transesofagic ecocardiography, measurement of the pulmonary arterial pressure or of cardiac debit should be reserved for patients with a low cardiac reserve [31].

Although the blood is stored in the operating theatre and available for immediate use, it is necessary to establish a safety margin. After collecting the blood, a red blood cell (erythrocyte) and hematocrit count should be performed, as well as arterial and venous gasometry and the dosage of plasma lactate [3].

The lactate should remain below 2 - $3 \mathrm{mg} / \mathrm{dl}$. In case of increased plasma lactate hypovolemia should be suspected and treat initially with fluids. If it does not return to base values or in case of hemodynamic instability or other signs of tissue suffering, one collection bag should be reinfused and new exams requested (plasma lactate or mixed venous saturation, in case a central line is available) [12].

\subsection{Replacing the Collected Blood}

Choosing the correct time for reinfusion is one of the determining aspects of ANH efficiency for economizing homologous blood [32]. The replacement of the blood should be dictated by both surgical and patient conditions. In case of uncontrollable hemorrhage, replacing the collected blood during the ANH process will be necessary before completion of the surgery. In case of very light 
continual losses, it is possible for the replacement to be made only in the end of surgery. Patients under cardiac surgery with extracorporeal circulation are potentially benefitted when the blood is replaced after protamine [33].

In some spetial cases when large amount of bleeding is expected in postoperative period (thoracic drains, for example), blood can be storaged and reinfused in the postanesthesia recuperation room or whilst in the intensive care unit.

In ANH is not necessary to use equipment fitted with filters, so that there is no wastage of platelets [34].

If the patient shows symptoms of hypervolemia following reinfusion, it may be necessary to give an infusion of diuretics (furosemide $0.5-2 \mathrm{mg} / \mathrm{kg}$ ) [12].

During the collection process of ANH, each subsequent unit will be progressively more and more diluted. Therefore, at the time of reinfusion, it is recommended that the last unit collected will be the first to be replaced [3].

\subsection{Costs}

When performing an ANH procedure, bags for blood collection are necessary (approximately US $\$ 8.00$ each), three-way infusion devices (US $\$ 1.00$, each), equipment common to both (US $\$ 0.30$, each) and additional laboratory exams (costs vary for each hospital) [19]. In Brazil, the collection bags can be requested directly from the Hemocenters in each state or they can be easily purchased, from various pharmaceutical Industrial sites on net.

Meta-analysis used to evaluate alternative techniques (PAD, ANH and cell salvage) concluded that ANH is the cheapest strategy and most cost effective among all the options, as this procedure is cheaper than the transfusion of a bag of homologous blood [19].

\subsection{Utilization in Patients That Refuse Blood Transfusions}

When ANH is performed with patients who have restrictions on receiving blood transfusions for religious reasons, in the case of a Jehovah's Witness for example, a closed circuit system should be prepared, and some modifications are necessary [35-37].

The system for collecting and reinfusion of blood should be maintained permanently connected to the patient's intra-vascular compartment.

The collection bags should be pre-connected to the venous channel, through a series of three way connectors ("little taps").

As soon as the collection bag is full the connector should be filled with acellular fluids, to avoid coagulation.
The bags containing whole blood should remain on a slow drip in order to ensure a continuous flow into the patient.

In case the blood is not fully administered during the surgical procedure, the patient and family should be kept informed about the character of any blood administered post-operatively.

\subsection{Problems, Pitfalls and Controversies}

It is really challenging to the anesthesiologist to perform ANH in the same time as the surgery is taking place, with all its potential critical tasks [33].

Hemodynamic repercussions can occur in case collections are made too quickly (less than 15 minutes), such as hypotension and/or taquicardia. Patients with coronary diseases are unable to tolerate ANH and show symptoms of cardiac ischemia during the process of collection or reinfusion of blood, due to temporary hypervolemia [12].

The blood should remain under the direct control of the anesthesiologist throughout the process and in no circunstance should it be sent to the blood bank without his expressed knowledge or indication [3].

ANH is an alternative therapy to blood transfusion, but it is surrounded by countless controversies [31], especially with regards to the safety of iatrogenic production of the anemic condition, although that study has been unable to detect any evidence of inadequate oxygen supply in volunteers submitted to hemoglobin concentrations of $5 \mathrm{~g} / \mathrm{dl}$, as well as in oxygen supply as low as $7.3 \mathrm{ml}$ $\mathrm{O}_{2} / \mathrm{kg} / \mathrm{min}$ [38].

In relation to hemorrhagic diathesis, such as coagulation factors being sequestered for the collection bags, it is reasonable to suppose that the patient presents tendencies for bleeding [8]. However, meta-analysis demonstrated that there was no increase in bleeding until the concentration coagulation factors decreased to $20 \%$ of their original value [7]. Thrombocytopenia and dilutional hyperfibrinogenemia can even occur but in general the process of ANH encourages a pro-coagulant effect [18].

The effectiveness of ANH can be examined in terms of their results, obtained through theoretical calculations in relation to the volume of blood "saved" [31,39]; reducing the need for allogenic transfusions [40], as well as in the maximum permitted blood loss [39]. The blood volume saved can be calculated through mathematical models using known and variable parameters. Some of these studies concluded that the benefit was only modest [31], whilst others considered the effectiveness of ANH to be significant, bearing in mind that the transfusional "trigger" will always be based on a clinical and not on a numerical evaluation $[39,41]$.

Since the 70's, more than 250 studies on ANH have been published. Most of them concluded that ANH can be beneficial in avoiding transfusion or in reducing the 
amount transfused. However, some studies were unable to demonstrate the benefits of using this procedure; this was probably due to differences in the study design, randomization, in the quantity of blood collected or in the uniformity of the criteria used for blood reinfusion or alogenic transfusion.

\section{Final Considerations}

ANH is underused, because it is very often misunderstood. Its ability as a blood conservation therapy is directly related to the amount of blood that we are able to collect from the patient, i.e. the greater the volume collected, the greater the effectiveness of ANH [42].

As this procedure is performed in a predominantly manual manner and requires constant vigilance, many anesthesiologists are not very motivated to use this procedure, due to the additional work required. However, with frequent use, they will familiarize themselves with the technique and can realize the true benefits of its utilization [42].

\section{REFERENCES}

[1] L. T. Goodnough, "Acute Normovolaemic Haemodilution,” Vox Sanguinis, Vol. 83, No. 1, 2002, pp. 211-215. doi:10.1111/j.1423-0410.2002.tb05304.x

[2] D. Murray, “Acute Normovolemic Hemodilution,” European Spine Journal, Vol. 13, No. 1, 2004, pp. 72-75. doi:10.1007/s00586-004-0755-8

[3] A. Shander and T. S. Rijhwani, "Acute Normovolemic Hemodilution,” Transfusion, Vol. 44, No. 12, 2004, pp. 26S-34S. doi:10.1111/j.0041-1132.2004.04293.x

[4] L. T. Goodnough and T. G. Monk, "Autologous Transfusion, Recombinant Factor VIIa, and Bloodless Medicine,” In: R. D. Miller, Ed., Miller's Anesthesia, 7th Edition, 2009.

[5] G. J. Crystal and M. R. Salem, "Hemodynamic Compensation during Acute Normovolemic Hemodilution," Anesthesiology, Vol. 100, No. 4, 2004, pp. 1034-1035.

[6] T. G. Monk, “Acute Normovolemic Hemodilution,” Anesthesiology Clinics North America, Vol. 23, No. 2, 2005, pp. 271-281. doi:10.1016/j.atc.2005.03.002

[7] G. L. Bryson, A. Laupacis and G. A. Wells, "Does Acute Normovolemic Hemodilution Reduce Perioperative Allogeneic Transfusion? A Meta-Analysis," Anesthesia and Analgesia, Vol. 86, No. 1, 1998, pp. 9-15.

[8] J. C. Drummond, C. T. Petrovitch and T. A. Lane, "Hemostasis and Transfusion Medicine,” In: P. G. Barash, B. F. Cullen, R. K. Stoelting, M. K. Cahalan and M. C. Stock, Eds., Clinical Anesthesia, 6th Edition, 2009, pp. 369-410.

[9] C. Lentschener and Y. Ozier, “Acute Normovolemic Hemodilution: The Subgroup of Patients Likely to Benefit Remains Uncertain,” Anesthesiology, Vol. 98, No. 6, 2003, p. 1519. doi:10.1097/00000542-200306000-00041

[10] L. T. Goodnough, B. Skikne and C. Brugnara, "Erythro- poietin, Iron and Erythropoiesis,” Blood, Vol. 96, No. 3, 2000, pp. 823-833.

[11] I. Petrašovicová, P. Sklienka, L. Kolár, J. Jahoda and R. Kula, "The Clinical Relevance of the Fluid Balance in Critically Ill Patients,” Critical Care, Vol. 4, No. 1, 2000, p. 19. doi:10.1186/cc739

[12] M. Jamnicki, R. Kocian, P. van der Linden, M. Zaugg and D. R. Spahn, "Acute Normovolemic Hemodilution: Physiology, Limitations, and Clinical Use,” Journal of Cardiothoracic and Vascular Anesthesia, Vol. 17, No. 6, 2003, pp. 747-754. doi:10.1053/j.jvca.2003.09.018

[13] P. G. Loubser and A. Chan, "Prediction of the Effect of Acute Normovolemic Hemodilution on the Hematological Constituents of Sequestered Autologous Whole Blood," Anesthesia and Analgesia, Vol. 102, No. 4, 2006, pp. 991997. doi:10.1213/01.ane.0000198700.41026.2e

[14] G. Singbartl, K. Singbartl and W. Schleinzer, "Is Acute Normovolemic Hemodilution Cost-Effective?” Transfusion, Vol. 36, No. 9, 1996, pp. 849-850. doi:10.1046/j.1537-2995.1996.36996420770.x

[15] P. Innerhofer, D. Fries, A. Klingler and W. Streif, “In Vivo Effect of Haemodilution with Saline on Coagulation,” British Journal of Anaesthesia, Vol. 89, No. 6, 2002, pp. 934-939. doi:10.1093/bja/aef574

[16] L. T. Goodnough, T. G. Monk and M. E. Brecher, “Acute Normovolemic Hemodilution Should Replace the Preoperative Donation of Autologous Blood as a Method of Autologous-Blood Procurement,” Transfusion, Vol. 38, No. 5, 1998, pp. 473-476. doi:10.1046/j.1537-2995.1998.38598297217.x

[17] D. A. Henry, P. A. Carless, A. J. Moxey, D. O’Connell, M. A. Forgie, P. S. Wells and D. Fergusson, "Preoperative Autologous Donation for Minimising Perioperative Allogeneic Blood Transfusion," Cochrane Database of Systematic Reviews, No. 2, 2002, Article ID: CD003602.

[18] S. Hill, P. A. Carless, D. A. Henry, J. L. Carson, P. P. C. Hebert, K. M. Henderson and B. McClelland, "Transfusion Thresholds and Other Strategies for Guiding Allogeneic Red Blood Cell Transfusion," Cochrane Database of Systematic Reviews, No. 1, 2000, Article ID: CD002042. doi:10.1002/14651858.CD002042

[19] L. Davies, T. J. Brown, S. Haynes, K. Payne, R. A. Elliott and C. McCollum, "Cost-Effectiveness of Cell Salvage and Alternative Methods of Minimising Perioperative Allogeneic Blood Transfusion: A Systematic Review and Economic Model," Health Technology Assessment, Vol. 10, No. 44, 2006, pp. 1-210.

[20] K. Singbartl, P. Innerhofer, J. Radvan, B. Westphalen, D. Fries, R. Stogbauer and H. Van Aken, "Hemostasis and Hemodilution: A Quantitative Mathematical Guide for Clinical Practice,” Anesthesia and Analgesia, Vol. 96, No. 4, 2003, pp. 929-935. doi:10.1213/01.ANE.0000052711.68903.5D

[21] C. Madjdpour and D. R. Spahn, “Allogeneic Red Blood Cell Transfusions: Efficacy, Risks, Alternatives and Indications," British Journal of Anaesthesia, Vol. 95, No. 1, 2005, pp. 33-42. doi:10.1093/bja/aeh290

[22] J. B. Gross, "Estimating Allowable Blood Loss: Cor- 
rected for Dilution,” Anesthesiology, Vol. 58, No. 3, 1983, pp. 277-280. doi:10.1097/00000542-198303000-00016

[23] S. B. Jones, C. W. Whitten and T. G. Monk, "Influence of Crystalloid and Colloid Replacement Solutions on Hemodynamic Variables during Acute Normovolemic Hemodilution,” Journal of Clinical Anesthesia, Vol. 16, No. 1, 2004, pp. 1-17. doi:10.1016/j.jclinane.2003.03.003

[24] D. S. Prough and A. Bidani, "Hyperchloremic Metabolic Acidosis Is a Predictable Consequence of Intraoperative Infusion of 0.9\% Saline,” Anesthesiology, Vol. 90, No. 5, 1999, pp. 1247-1249. doi:10.1097/00000542-199905000-00003

[25] E. L. Williams, K. L. Hildebrand, A. S. McCormick and M. J. Bedel, “The Effect of Intravenous Lactated Ringer's Solution versus $0.9 \%$ Sodium Chloride Solution on Serum Osmolality in Human Volunteers,” Anesthesia and Analgesia, Vol. 88, No. 5, 1999, pp. 999-1003.

[26] D. A. Otsuki, D. T. Fantoni, C. B. Margarido, C. K. Marumo, T. Intelizano, C. A. Pasqualucci and J. O. C. Auler Jr., "Hydroxyethyl Starch Is Superior to Lactated Ringer as a Replacement Fluid in a Pig Model of Acute Normovolaemic Haemodilution,” British Journal of Anaesthesia, Vol. 98, No. 1, 2007, pp. 29-37. doi:10.1093/bja/ael312

[27] L. M. T. Araújo, "Hemodiluição normovolêmica com solução hipertônica a 7.5\%. Parâmetros hemodinâmicos, efeitos metabólicos e repercussões laboratoriais,” Ph.D. Dissertation, Faculdade de Medicina de Ribeirão Rreto, Ribeirão Preto, 2008.

[28] D. Drobin and R. G. Hahn, "Efficiency of Isotonic and Hypertonic Crystalloid Solutions in Volunteers," Anesthesiology, Vol. 96, No. 6, 2002, pp. 1371-1380. doi:10.1097/00000542-200206000-00016

[29] D. J. Ciesla, E. E. Moore, R. J. Musters, W. L. Biffl and C. C. Silliman, "Hypertonic Saline Alteration of the PMN Cytoskeleton: Implications for Signal Transduction and the Cytotoxicity Response," Journal of Trauma, Vol. 50, No. 2, 2001, pp. 206-212. doi:10.1097/00005373-200102000-00004

[30] J. A. Kolsen-Petersen, "Immune Effect of Hypertonic Saline: Fact or Fiction?” Acta Anaesthesiologica Scandinavica, Vol. 48, No. 6, 2004, pp. 667-678. doi:10.1111/j.1399-6576.2004.00396.x

[31] J. F. Feldman, J. V. Roth and D. G. Bjoraker, "Maximum Blood Savings by Acute Normovolemic Hemodilution," Anesthesia and Analgesia, Vol. 80, No. 1, 1995, pp. 108113.

[32] O. P. Habler, M. S. Kleen, J. W. Hutter, A. H. Podtschaske, M. Tiede, G. I. Kemming, M. V. Welte, C. O. Corso, S. Batra, P. E. Keipert, N. S. Faithfull and K. F. Messmer, "Does Acute Normovolemic Hemodilution Reduce Perioperative Allogeneic Transfusion? A Meta-Analysis. The International Study of Perioperative Transfusion,”
Anesthesia and Analgesia, Vol. 86, No. 1, 1998, pp. 9-15.

[33] J. B. Segal, E. Blasco-Colmenares, E. J. Norris and E. Guallar, "Preoperative Acute Normovolemic Hemodilution: A Meta-Analysis,” Transfusion, Vol. 44, No. 5, 2004, pp. 632-644. doi:10.1111/j.1537-2995.2004.03353.x

[34] A. Trouwborst, J. van Bommel, C. Ince and C. P. Henny, "Monitoring Normovolaemic Haemodilution," British Journal of Anaesthesia, Vol. 81, Suppl. 1, 1998, pp. 73-78.

[35] M. Gohel, R. Bulbulia, F. Slim, K. Poskitt and M. Whyman, "How to Approach Major Surgery Where Patients Refuse Blood Transfusion (Including Jehovah's Witnesses)," Annals of the Royal College of Surgeons of England, Vol. 87, No. 1, 2005, pp. 3-14. doi:10.1308/1478708051414

[36] L. Milligan and M. Bellamy, “Anaesthesia and Critical Care of Jehovah's Witnesses. Continuing Education in Anaesthesia," Critical Care \& Pain, Vol. 4, No. 2, 2004, pp. 35-39.

[37] M. K. Viele and R. B. Weiskopf, "What Can We Learn about the Need for Transfusion from Patients Who Refuse Blood? The Experience with Jehovah's Witness," Transfusion, Vol. 34, No. 5, 1994, pp. 396-401. doi:10.1046/j.1537-2995.1994.34594249050.x

[38] E. C. M. S. Van Woerkens, A. Trouwborst and J. J. B. van Lanschot, "Profound Hemodilution: What Is the Critical Level of Hemodilution at Which Oxygen Delivery-Dependent Oxygen Consumption Starts in an Anesthetized Human?” Anesthesia and Analgesia, Vol. 75, No. 5, 1992, pp. 818-821.

[39] S. Kahraman, K. H. Altunkaya, B. Celebioglu, M. Kanbak, I. Pasaoglu and K. Erdem, "The Effect of Acute Normovolemic Hemodilution on Homologous Blood Requirements and Total Estimated Red Blood Cell Volume Lost,” Acta Anaesthesiolica Scandinavica, Vol. 41, No. 5, 1997, pp. 614-617. doi:10.1111/j.1399-6576.1997.tb04752.x

[40] M. Jacob, D. Bruegger, P. Conzen, B. F. Becker, U. Finsterer and M. Relum, "Development and Validation of a Mathematical Algorithm for Quantifying Preoperative Blood Volume by Means of the Decrease in Hematocrit Resulting from Acute Normovolemic Hemodilution," Transfusion, Vol. 45, No. 4, 2005, pp. 562-571. doi:10.1111/j.0041-1132.2005.04292.x

[41] R. B. Weiskopf, "Efficacy of Acute Normovolemic Hemodilution Assessed as a Function of Fraction of Blood Volume Lost,” Anesthesiology, Vol. 94, No. 3, 2001, pp. 439-446. doi:10.1097/00000542-200103000-00013

[42] A. Shander and L. T. Goodnough, "Objectives and Limitations of Bloodless Medical Care," Current Opinion in Hematology, Vol. 13, No. 6, 2006, pp. 462-470. doi:10.1097/01.moh.0000245692.32085.bd 